\title{
Teores de cloretos, lactose e índice cloretos/lactose na secreção láctea de bovinos da raça Jersey no primeiro mês da lactação
}

\author{
[Chloride and lactose contents and chloride/lactose ratio in milk from Jersey cows
} in the first month of lactation]

\author{
R.F.S. Raimondo ${ }^{1,3}$, D.B. Birgel ${ }^{1}$, J.P.E. Saut ${ }^{1}$, E.R. Komninou ${ }^{1}$, E.H. Birgel Junior ${ }^{2 *}$ \\ ${ }^{1}$ Aluno de pós-graduação - FMVZ-USP - São Paulo, SP \\ ${ }^{2}$ Faculdade de Medicina Veterinária e Zootecnia - USP \\ Av. Prof. Dr. Orlando Marques de Paiva, 87 \\ 05508-900 - São Paulo, SP \\ ${ }^{3}$ Bolsista da FAPESP
}

\begin{abstract}
RESUMO
Avaliou-se a influência do período colostral nos teores lácteos de cloretos, lactose e do índice cloretos/lactose. Foram colhidas 418 amostras de leite provenientes de glândulas mamárias sadias, e que não apresentavam crescimento bacteriano ao exame microbiológico, de 127 vacas da raça Jersey. As amostras foram distribuídas em oito grupos: $0-1 / 2$ dia; $1 / 2-1$ dia; $1-2$ dias; $2-3$ dias; $3-5$ dias; 5 - 7 dias; 7 - 15 dias; 15 - 30 dias em lactação. Nas amostras, colhidas antes da ordenha, foram determinados os valores de cloretos, por titulação colorimétrica, e de lactose, por radiação infravermelho, e calculou-se o índice cloretos/lactose. Nas primeiras 24 horas da lactação, observou-se abrupta diminuição no teor lácteo de cloretos e do índice cloretos/lactose, associada com o aumento no teor lácteo de lactose. A transição da secreção de colostro para leite em relação ao teor de cloretos e lactose e ao índice cloretos/lactose na secreção láctea ocorreu na primeira semana da lactação, a partir do terceiro dia da lactação para o valor de cloretos e para a relação cloretos/lactose e a partir do quarto dia da lactação para o teor de lactose. Recomenda-se, nas primeiras 24 horas da lactação, a adoção dos seguintes limites de normalidade: cloretos, $\leq 173,4 \mathrm{mg} / \mathrm{dL}$; lactose $\geq 3,94 \mathrm{~g} / \mathrm{dL}$ e índice cloretos/lactose, $\leq 6,11 \%$. Entre o segundo e o sétimo dia da lactação (transição de colostro para leite), indicamse os seguintes limites: cloretos $\leq 125,9 \mathrm{mg} / \mathrm{dL}$; lactose, $\geq 4,03 \mathrm{~g} / \mathrm{dL}$ e índice cloretos/lactose $\leq 3,54$.
\end{abstract}

Palavras-chave: vaca, leite, colostro, cloretos, lactose, raça Jersey

\begin{abstract}
In order to assess the influence of the colostral period on chloride and lactose levels and on the chloride/lactose ratio, 419 milk samples from 127 Jersey cows were analyzed. The samples were collected from healthy udders that did not present any bacterial growth in the microbiological examination. Cows were distributed into eight groups as follows: $0-1 / 2$ day; $1 / 2-1$ day; 1 - 2 days; 2 - 3 days; $3-15$ days; 5 - 7 days; $7-15$ days; $15-30$ days of lactation. The samples were collected before milking to analyze the levels of chloride by colorimetric titration, lactose by infrared radiation, and to determine the chloride/lactose ratio. In the first 24 hours after partition, there was an abrupt reduction in chloride levels as well in chloridel lactose ratio, associated with an increase in lactose levels. It was observed that the transition of the secretion from colostrum to milk, regarding chloride and lactose levels and chloride/lactose ratio occurred during the first week of lactation: from the $3^{\text {rd }}$ day of lactation for chloride and chloride/lactose ratio and from $4^{\text {th }}$ for the lactose levels. It is recommended the use the following thresholds as normal ranges for the first 24 hours of lactation: chloride $\leq 173.4 \mathrm{mg} / \mathrm{dL}$; lactose $\geq 3.94 \mathrm{~g} / \mathrm{dL}$, and chloride/lactose ratio $\leq 6.11 \%$; and between $2^{\text {nd }}$ and $7^{\text {th }}$ days of lactation (transition from colostrum to milk), it was suggested the use of the following values: chloride $\leq 125.9 \mathrm{mg} / \mathrm{dL} ;$ lactose $\geq 4.03 \mathrm{~g} / \mathrm{dL}$ and chloride/lactose ratio $\leq 3.54$.
\end{abstract}

Keywords: cow, milk, colostrum, chloride, lactose, Jersey

Recebido em 20 de setembro de 2007

Aceito em 23 de setembro de 2008

*Autor para correspondência (corresponding author)

E-mail: ehbirgel@usp.br

Apoio: FAPESP processo $n^{\circ}$ 04/12049-5 


\section{INTRODUÇÃO}

Dentre os fatores responsáveis pelas alterações na composição e nas propriedades físicoquímicas do leite, merecem destaque aquelas decorrente das mamites que podem acometer bovinos em qualquer das fases da lactação. No diagnóstico das mamites, o clínico veterinário deve realizar, além do exame físico da glândula mamária, uma série de testes e provas complementares que avaliam a resposta inflamatória e/ou a extensão da lesão provocada. Entre essas provas, destacam-se as determinações de cloretos, lactose e do índice cloretos/lactose, pois os processos inflamatórios na glândula mamária podem ocasionar lesões teciduais responsáveis por alterações na síntese de lactose associadas à destruição do epitélio secretor, alterações na permeabilidade vascular e impedimento do transporte dos íons nas células danificadas pelo processo inflamatório, determinando aumento das concentrações de sódio, cloro e bicarbonato, e pela diminuição da concentração de potássio (Kitchen, 1981).

O conhecimento de patologia clínica, nas últimas três décadas, no Brasil, apresentou uma considerável evolução, permitindo o estabelecimento dos valores de referência para as características físico-químicas do leite obtido durante a lactação plena, bem como a avaliação da influência de diversos fatores (fase da lactação, quarto mamário, fase de ordenha, tipo de exploração leiteira, presença da infecção bacteriana, ocorrência da mamite e retenção do leite). Contudo, não foram estabelecidos os padrões de referência para os diversos constituintes do leite de vacas sadias durante a fase colostral (Birgel Junior, 2006).

No período colostral, ocorrem significativas modificações da constituição láctea, sendo que Amaral et al. (1988) e Estrella (2001) relataram que o valor máximo do teor lácteo de cloretos foi observado durante a fase colostral, conferindo a essa fração láctea um sabor salgado, similar ao encontrado em animais com mamites (Birgel, 2004). Roy (1980) e Estrella (2001) descreveram que, na fase colostral, foram encontrados valores mínimos de lactose. Esse último autor ressaltou que o valor do índice cloretos/lactose no colostro foi maior do que o determinado no leite de vacas em plena lactação. Com a evolução da lactação, a secreção de colostro é gradativamente substituída pela secreção de leite, sendo necessária a adoção de valores padrões de referência, especialmente determinados para a primeira semana da lactação (Birgel Junior, 2006).

A presente pesquisa teve a finalidade de avaliar os teores lácteos de cloretos, lactose e índice cloretos/lactose no primeiro mês da lactação, procurando estabelecer os valores de referência das mencionadas variáveis durante a fase colostral.

\section{MATERIAL E MÉTODOS}

Foram utilizadas 418 amostras de leite sem crescimento bacteriano no exame microbiológico proveniente de 127 vacas. As amostras de secreção láctea foram agrupadas em oito momentos, de acordo com a fase da lactação em que se encontravam (Tab. 1).

O material utilizado, colhido em propriedades situadas no estado de São Paulo, originou-se de vacas mantidas em sistema de criação semiextensivo. Os animais recebiam volumoso com suplementação de silagem e concentrado comercial. Nessas propriedades, adotava-se o sistema de ordenha mecânica. Antes da ordenha, realizava-se a higiene do úbere, por meio da imersão dos tetos em solução antisséptica à base de cloro, e a secagem com toalha de papel ou pano com solução antisséptica. Após a ordenha, os tetos eram novamente imersos em uma solução antisséptica à base de iodo.

A seleção das glândulas mamárias foi baseada no exame clínico, não sendo utilizadas aquelas que apresentassem episódios recorrentes de mamite ou alterações das características macroscópicas do leite, como presença de grumos, detectadas na prova do fundo escuro, ou que, à palpação da glândula mamária, realizada após a ordenha, apresentassem alterações de consistência que pudessem estar relacionadas à existência de um processo inflamatório agudo ou crônico, conforme as recomendações de Birgel (2004). 
Tabela 1. Constituição dos grupos experimentais para estabelecer os valores de referência dos teores de cloretos, lactose e índice cloretos/lactose na secreção láctea de vacas da raça Jersey, no primeiro mês da lactação

\begin{tabular}{ccccc}
$\begin{array}{c}\text { Grupo } \\
\text { experimental }\end{array}$ & \multicolumn{2}{c}{ Fase da lactação } & $\begin{array}{c}\text { Número de } \\
\text { quartos }\end{array}$ & $\begin{array}{c}\text { Número de } \\
\text { animais }\end{array}$ \\
\hline A & $0-1 / 2$ dia & $0-12$ horas & 27 & 11 \\
B & $1 / 2-1$ dia & $12-24$ horas & 41 & 11 \\
C & $1-2$ dias & $24-48$ horas & 47 & 15 \\
D & $2-3$ dias & $48-72$ horas & 50 & 14 \\
E & $3-5$ dias & $72-120$ horas & 86 & 25 \\
F & $5-7$ dias & $120-168$ horas & 48 & 13 \\
G & $7-15$ dias & $168-360$ horas & 62 & 21 \\
H & $15-30$ dias & $360-720$ horas & 57 & 17 \\
Total & & & 418 & 127 \\
\hline
\end{tabular}

A colheita das amostras foi realizada na sala de ordenha, imediatamente antes da ordenha. Após os procedimentos rotineiros de preparo dos animais para a ordenha, fez-se a assepsia da extremidade do teto, particularmente do orifício do teto, utilizando um chumaço de algodão embebido em álcool $70 \%$, de acordo com os padrões recomendados pelo IDF (Laboratory..., 1981). Após essa assepsia, dois ou três jatos de leite foram desprezados, de tal forma a garantir que o leite acumulado nas cisternas do teto e da glândula, no período entre as ordenhas, não fosse incluído na amostra, para então se fazer a colheita do material em alíquotas destinadas ao exame microbiológico e à avaliação das características físico-químicas (cloretos, lactose e índice cloretos/lactose).

Foram colhidas amostras de $50 \mathrm{~mL}$ em frascos de plástico, acondicionados em caixas de isopor refrigeradas com gelo reciclável durante o transporte, até o momento de serem processadas, para a determinação dos teores de cloretos. Os exames foram concluídos antes de 12 horas de conservação.

Na sequência, para a determinação dos teores de lactose, cerca de $40 \mathrm{~mL}$ de leite foram colhidos em frascos de plásticos contendo pastilhas do conservante bronopol (2-bromo 2-nitropropano 1,3- diol), mantidas à temperatura ambiente, e enviados para o laboratório, onde as análises foram realizadas em até sete dias após a colheita.
A determinação dos teores de cloretos na secreção láctea foi realizada por titulação coloumétrica $^{1}$, na qual os íns de cloro presentes no leite reagem com a prata liberada no meio ácido, formando o sal cloreto de prata. Os resultados eram expressos em $\mathrm{mmol} / \mathrm{L}$ e convertidos pelo fator de 3,55 para a unidade $\mathrm{mg} / \mathrm{dL}$. Para a determinação dos teores de lactose, as amostras de leite, antes do início da análise, eram mantidas em banho-maria a $38^{\circ} \mathrm{C}$, durante 15 minutos, homogeneizadas manualmente, sendo a sua quantificação realizada por radiação infravermelho ${ }^{2}$ e os resultados expressos em $\mathrm{g} / \mathrm{dL}$. $\mathrm{O}$ índice cloretos/lactose foi obtido mediante a divisão do valor de cloretos pelo valor da lactose, ambos expressos em mg/dL, multiplicado por 100 , e os resultados apresentados em porcentagem.

Os resultados foram apresentados em média, desvio-padrão e intervalo de confiança, sendo que os dados foram primeiramente submetidos ao teste de Levene para avaliar a homocedasticidade (homogeneidade de variâncias) entre os grupos experimentais. Verificou-se que, as variáveis cloretos e índice cloretos/lactose apresentavam, após a transformação logarítmica dos dados, homogeneidade na variância entre os grupos, permitindo que os dados fossem submetidos à análise de variância seguida da comparação dos

${ }^{1}$ Analisador de Cloretos Modelo 925 da Corning - EUA. ${ }^{2}$ Bentley Instruments Inc.- Peavey Road Chaska, EUA. 
pares de médias pelo método de Bonferroni. Para a variável lactose, a homocedasticidade não foi aceita, mas a razão entre a maior e a menor variância era menor que 5, permitindo que os dados fossem submetidos à análise de variância seguida da comparação dos pares de médias pelo método de comparações múltiplas de Dunnett T3 (Berquó et al., 1981; Sampaio, 1998).

\section{RESULTADOS E DISCUSSÃO}

O teor lácteo de cloretos variou em função do período colostral (Fig. 1). Nos grupos compostos por amostras colhidas com até 12 horas após o parto $(154,10 \pm 29,3 \mathrm{mg} / \mathrm{dL})$ e entre 12 e 24 horas após o parto $(155,50 \pm 56,66 \mathrm{mg} / \mathrm{dL})$, foram encontrados valores mais elevados que os observados entre o segundo e $30^{\circ}$ dia da lactação. Estas observações assemelham-se às de Amaral et al. (1988), Estrella (2001) e Birgel Junior (2006), que relataram, também, ser o valor máximo do teor lácteo de cloretos observado durante o período colostral, conferindo a essa fração láctea um sabor salgado, similar ao encontrado em animais com mamites (Birgel, 2004).

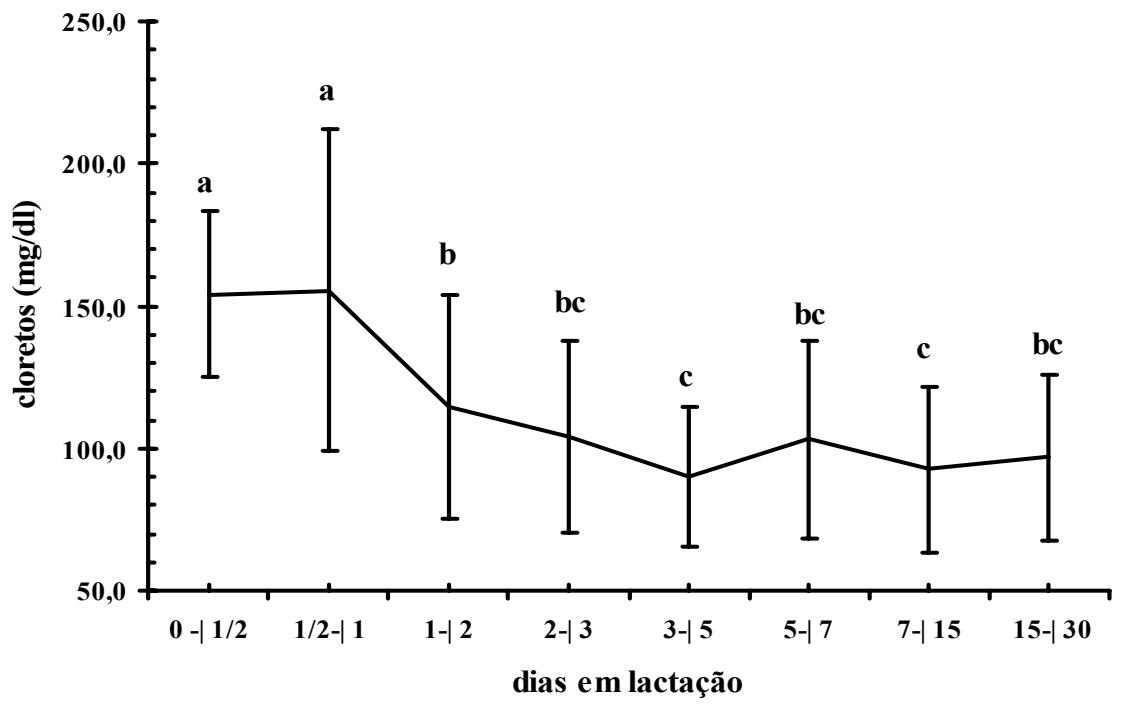

Letras diferentes significam diferença estatística entre os valores $(\mathrm{P} \leq 0,05)$ pelo teste de Bonferroni.

Figura 1. Teores de cloretos na secreção láctea de bovinos da raça Jersey no primeiro mês da lactação.

Os teores de cloretos diminuíram gradualmente, atingindo, no grupo composto por amostras colhidas entre 48 e 72 horas da lactação, valores iguais a $104,40 \mathrm{mg} / \mathrm{dL}$. A partir desse momento, os teores de cloretos estabilizaram-se, apresentando valores similares àqueles citados como de referência para a raça Jersey por Raimondo e D'Angelino (2003). Birgel Junior (2006) também relatou que a transição de colostro para leite ocorria nos dois primeiros dias da lactação. Alguns autores encontraram resultados diferentes quanto ao momento de transição entre colostro e leite. Amaral et al. (1988) demonstraram que esses valores diminuíam entre o quarto e o sétimo dia da lactação, e Estrella (2001), entre o sétimo e $15^{\circ}$ dia da lactação.
Observou-se influência do período colostral sobre o teor lácteo de lactose (Fig. 2). Nas amostras colhidas com até 12 horas após o parto, foram observados os menores valores para essa variável $(3,14 \pm 0,66 \mathrm{~g} / \mathrm{dL}) \mathrm{e}$, nos primeiros dois dias da lactação, houve o aumento abrupto nos teores lácteos de lactose. Os valores encontrados nas amostras colhidas entre 24 e 48 horas da lactação $(4,18 \pm 0,50 \mathrm{~g} / \mathrm{dL})$ foram estatisticamente maiores que os verificados nas primeiras 24 horas da lactação. Roy (1980), Estrella (2001), Ontsouka et al. (2003), Mandsen et al. (2004) e Birgel Junior (2006) também descreveram que, no período colostral, foi encontrado valor mínimo do teor lácteo de lactose. Segundo Kitchen (1981), a lactose, como também os íons, o cloro, o sódio e o potássio são responsáveis pelo controle da pressão osmótica do leite. 


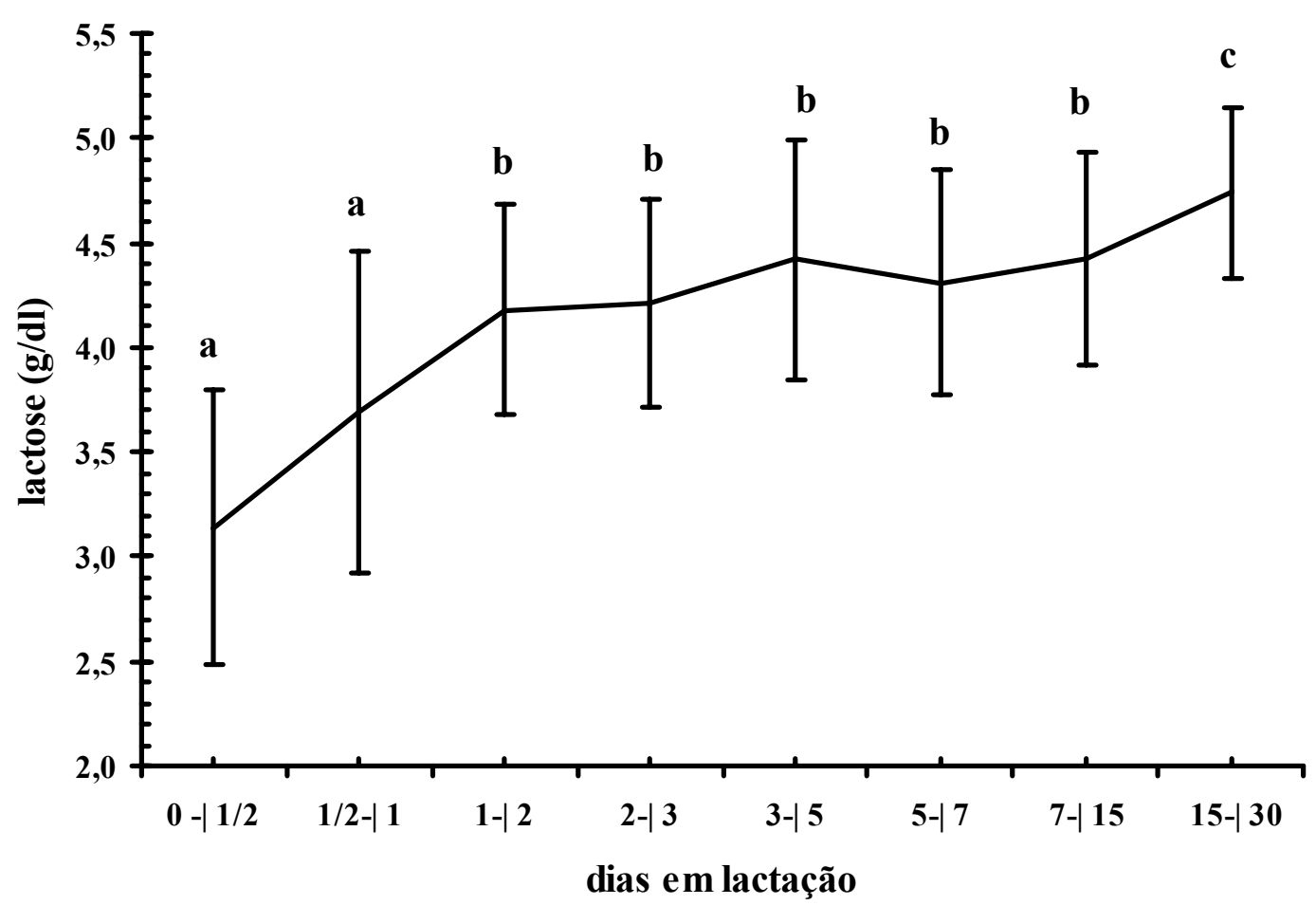

Letras diferentes significam diferença estatística entre os valores $(\mathrm{P} \leq 0,05)$ pelo teste de Dunnett $\mathrm{T} 3$.

Figura 2. Teores de lactose na secreção láctea de bovinos da raça Jersey no primeiro mês da lactação.

Entre o segundo e o $15^{\circ}$ dia da lactação, os teores lácteos de lactose oscilaram entre $4,18 \pm 0,50$ e $4,42 \pm 0,57 \mathrm{~g} / \mathrm{dL}$. Os valores obtidos nesse período foram estatisticamente menores do que os obtidos entre o $15^{\circ}$ e $30^{\circ}$ dia da lactação $(4,74 \pm 0,41 \mathrm{~g} / \mathrm{dL})$. Estas observações assemelhamse às referidas por Ng-Kwai-Hang et al. (1984), Estrella (2001), Ontsouka et al. (2003), Mandsen et al. (2004) e Birgel Junior (2006), que verificaram aumento dos teores de lactose durante o primeiro mês da lactação.

A transição de colostro para leite ocorreu a partir do quarto dia da lactação, pois os valores obtidos a partir deste momento são semelhantes àqueles referidos por Raimondo e D'Angelino (2003) como os de referência para vacas da raça Jersey. Em geral, há uma certa concordância entre os autores quanto ao momento em que ocorre essa transição. Estrella (2001) considerou como fase colostral amostras colhidas nos primeiros três dias da lactação, enquanto Birgel Junior (2006) observou que, em amostras colhidas entre o segundo e o terceiro dia da lactação, já podiam ser observados valores semelhantes aos verificados em vacas em plena lactação.

Nos primeiros dois dias da lactação, foram encontrados os valores máximos da relação cloretos/lactose (Fig. 3). Nos grupos compostos por amostras colhidas com até 12 horas após o parto $(5,22 \pm 1,84 \%)$ e entre 12 e 24 horas após o parto $(4,85 \pm 3,99 \%)$, foram encontrados valores significativamente maiores do que os observados entre o segundo e o $30^{\circ}$ dia da lactação. Estrella (2001) e Birgel Junior (2006) ressaltaram, também, que o valor do índice cloretos/lactose no colostro foi maior que o determinado no leite de vacas em plena lactação. A partir do terceiro dia da lactação, os valores dessa relação oscilaram entre $2,11 \pm 0,96$ e $2,61 \pm 1,38 \%$ e foram similares aos observados durante a lactação plena. Estes resultados assemelham-se aos de Birgel Junior (2006). 


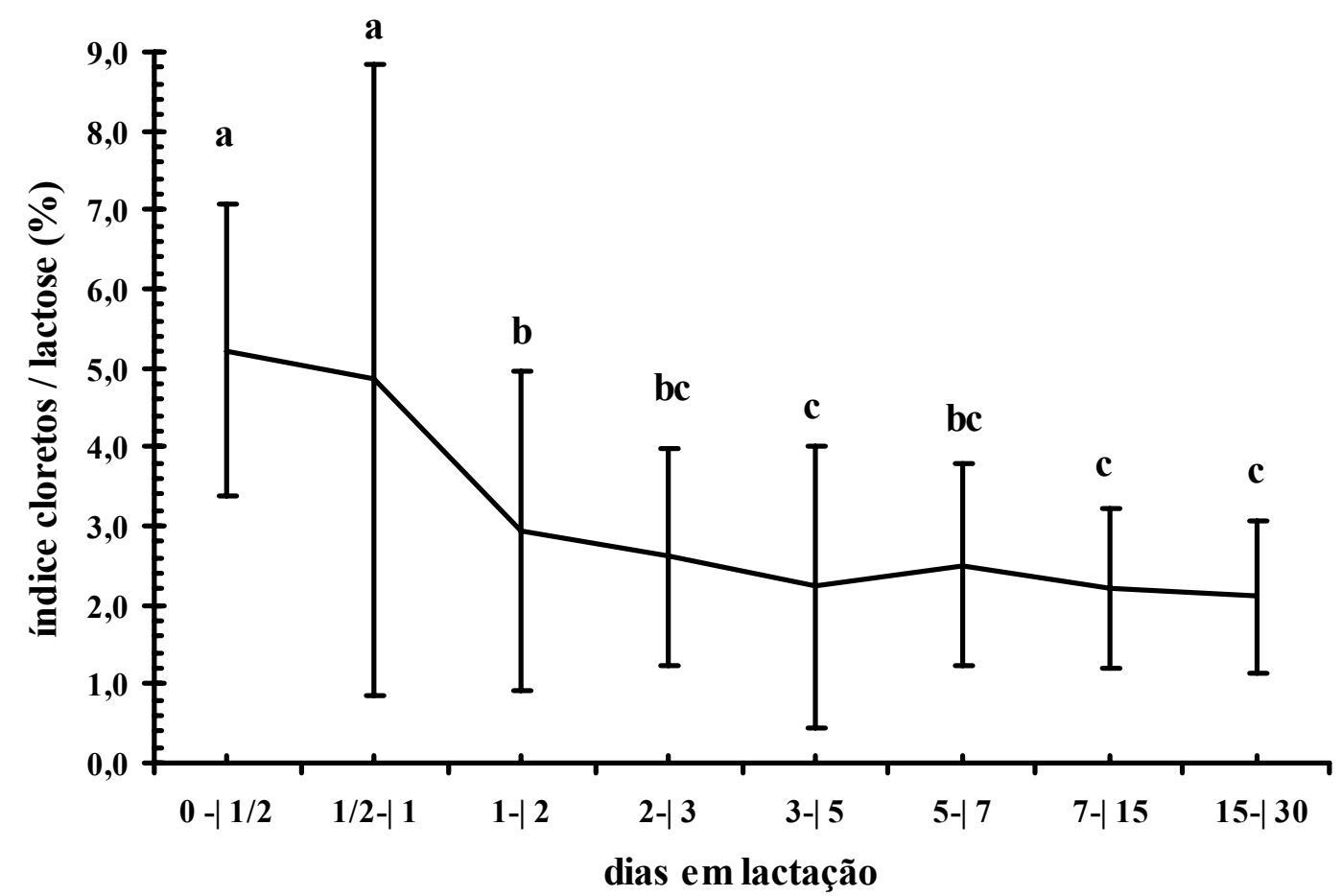

Letras diferentes significam diferença estatística entre os valores $(\mathrm{P} \leq 0,05)$ pelo teste de Bonferroni.

Figura 3. Valores do índice cloretos/lactose na secreção láctea de bovinos da raça Jersey no primeiro mês da lactação.

Considerando-se os intervalos de confiança estabelecidos nessas amostras de colostro, foram estabelecidos para bovinos sadios da raça Jersey os seguintes valores de referência: cloretos entre 137,7 e $173,4 \mathrm{mg} / \mathrm{dL}$; lactose entre 2,88 e $3,94 \mathrm{~g} / \mathrm{dL}$ e índice cloretos/lactose entre 3,59 e $6,11 \%$. A partir da determinação desses valores de referência, foram estabelecidos os seguintes limites de padrão de normalidade para cada uma das variáveis consideradas fundamentais para o diagnóstico das mamites no período colostral (primeiras 24 horas): cloretos, $\leq 173,4 \mathrm{mg} / \mathrm{dL}$; lactose $\geq 3,94 \mathrm{~g} / \mathrm{dL}$ e índice cloretos/lactose, $\leq 6,11 \%$.

A transição da secreção de colostro para leite ocorreu na primeira semana da lactação. Segundo Birgel Junior (2006), a magnitude das alterações observadas entre o sétimo e $305^{\circ}$ dia da lactação não justificaria, nesse momento, a adoção de valores de referência diferenciados, podendo, durante o período da lactação plena, ser utilizado um valor comum para o terço inicial, médio e final da lactação.
Assim, considerando-se as 231 amostras de secreção láctea sem crescimento bacteriano, obtidas entre o segundo e o sétimo dia da lactação, foram estabelecidos para bovinos sadios da raça Jersey os seguintes valores de referência para as características físico-químicas da secreção de transição do colostro para o leite: cloretos, entre 84,7 e $125,9 \mathrm{mg} / \mathrm{dL}$; lactose, entre 4,03 e $4,55 \mathrm{~g} / \mathrm{dL}$; e índice cloretos/lactose entre, 1,69 e 3,54\%. Durante esse período de transição de colostro para leite, recomenda-se a adoção dos seguintes limites de padrão de normalidade: cloretos, $\leq 125,9 \mathrm{mg} / \mathrm{dL}$; lactose $\geq 4,03 \mathrm{~g} / \mathrm{dL}$ e índice cloretos/lactose $\leq 3,54$.

\section{REFERÊNCIAS BIBLIOGRÁFICAS}

AMARAL, L.A.; NADER FILHO, A.; LEW, B.J. Estudo da variação do teor de cloretos no colostro e no leite de vacas abatidas. Ars Vet., v.4, p.105-112, 1988.

BERQUÓ, E.; SOUZA, J.M.P.; GLOTIEB, S.L.D. Bioestatística. São Paulo: CPU, 1981. $350 \mathrm{p}$. 
BIRGEL, E.H. Semiologia da glândula mamária de ruminantes. In: FEITOSA, F.L. Semiologia veterinária: a arte do diagnóstico. São Paulo: Roca, 2004. p.353-399.

BIRGEL JUNIOR, E.H. Caracteristicas fisicoquímicas, celulares e microbiológicas do leite de bovinos das raças Holandesa, Gir e Girolando, criados no estado de São Paulo. 2006. 335f. Tese (Livre Docência) - Faculdade de Medicina Veterinária e Zootecnia, Universidade de São Paulo, São Paulo.

ESTRELLA, S.L.G. Características fisicoquímicas e celulares do leite de bovinos da raça Holandesa, criados no estado de São Paulo. Influência da fase da lactação, dos quartos mamários, do número de lactações e do isolamento bacteriano. 2001. 162f. Dissertação (Mestrado) - Faculdade de Medicina Veterinária e Zootecnia, Universidade de São Paulo, São Paulo.

KITCHEN, B.J. Review of the progress of dairy science: bovine mastitis: milk compositional changes and related diagnosis test. J. Dairy Res., v.48, p.167-188, 1981.

LABORATORY methods for use in mastitis work. Bull. IDF, v.132, p.1-27, 1981.
MANDSEN, B.D.; RASMUSSEN, M.D., NIELSEN, M.O. et al. Physical properties of mammary secretions in relation to chemical changes during transition from colostrums to milk. J. Dairy Res., v.71, p.263-272, 2004.

NG-KWAI-HANG， K.F.; HAYES， J.F.; MOXLEY, J.E. et al. Variability of test-day milk production and composition and relation of somatic cell count with yield and compositional changes of bovine milk. J. Dairy Sci., v.67, p.361-366, 1984.

ONTSOUKA, C.E.; BRUCKMAIER, R.M.; BLUM, J.W. Fractionized milk composition during removal of colostrum and mature milk. $J$. Dairy Sci., v.86, p.2005-2011, 2003.

RAIMONDO, R.F.; D’ANGELINO, J.L. Análise físico-química do leite de vacas da raça Jersey criadas no estado de São Paulo. Rev. Hig. Alim., v.17, p.109-117, 2003.

ROY, J.H.B. The calf: management and feeding. London: Butterworth, 1980. 442p.

SAMPAIO, I.B.M. Estatística aplicada à experimentação animal. Belo Horizonte: FEPMVZ, 1998. 221p. 